\title{
Evaluation of the Discriminatory Power of USP Dissolution Method for Candesartan Cilexetil Tablets through Testing of Marketed Products in Egypt
}

\author{
Ahmed M. Amer ${ }^{1 *}$, Ahmed N. Allam ${ }^{2,3}$, and Ossama Y. Abdallah ${ }^{2}$ \\ ${ }^{1}$ Research and Development Department, Pharo Pharma Company, Alexandria, Egypt \\ ${ }^{2}$ Department of Pharmaceutics, Faculty of Pharmacy, Alexandria, Egypt \\ ${ }^{3}$ Department of Pharmaceutics and Pharmacy Practice, Ministry of Health, Muscat, Oman
}

e-mail: ahmed.medhat.amer@gmail.com

\begin{abstract}
The development of dissolution testing conditions for drugs exhibiting low aqueous solubility like candesartan cilexetil is a challenging task for pharmaceutical scientists and regulatory organizations. The purpose of this study was to evaluate the discriminatory power of the dissolution testing medium specified by USP, which is $0.35 \%$ polysorbate 20 in 0.05 $\mathrm{M}$ potassium dihydrogen phosphate $\mathrm{pH} 6.5$, for 4-, 8-, and 16-mg candesartan cilexetil tablets. We analyzed the drug release pattern and similarity factors of some generic products marketed in Egypt in comparison to the reference product (Atacand). It was found that, despite the ability of the method to effectively discriminate between the different 16-mg tablets, it failed to demonstrate any discriminative ability of the 4- and 8-mg doses without any formula alteration. Therefore, an attempt was made to develop a new medium for the 4- and 8-mg doses that could provide a reasonable sink condition and discriminatory power by reducing the percentage of polysorbate 20 in the medium from $0.35 \%$ to $0.1 \%$. The alternative dissolution medium demonstrated an acceptable sink condition and satisfactory discrimination power between the different marketed products, suggesting the use of this medium (0.1\% polysorbate 20 in $0.05 \mathrm{M}$ potassium dihydrogen phosphate, $\mathrm{pH} 6.5$ ) to aid in product development and testing of finished product quality.
\end{abstract}

KEYWORDS: Candesartan cilexetil, discriminatory power, dissolution, sink condition, similarity factor

\section{INTRODUCTION}

T he dissolution test was first introduced in the USP in 1962 as a quality control tool to ensure the reproducibility of and reduce the variation between different batches of formulations. The impact of using different pharmaceutical ingredients and the process of drug manufacturing on the bioavailability and the in vivo performance had not been appreciated (1). Later, dissolution testing was not only used as a quality control tool for monitoring the manufacturing process, but also as a tool to aid in formulation of generic products and optimization of formulas (2). At that point, the ability of dissolution testing conditions to demonstrate the effect of formula changes on the rate of drug dissolution became very important, which is described as the discriminatory power or the discriminative ability of the dissolution test (3).

For a drug to be absorbed from the gastrointestinal tract, it must be present in solution form, so in vitro dissolution testing helps to predict the bioavailability, especially for BCS Class II drugs because dissolution is considered the rate-limiting step for their absorption $(4,5)$. Designing a dissolution test for drugs exhibiting poor water solubility is a challenging process, as the dissolution medium should be able to dissolve the drug and provide sink conditions while not affecting the discriminatory power of the test (3). According to the USP, the sink condition is fulfilled when the dissolution medium is capable of dissolving the amount of drug that is three times greater than the amount of drug to be tested $(6,7)$.

Different approaches were adopted to maintain sink conditions such as increasing the medium volume, which is limited by the size of the dissolution vessel. Addition of organic solvents was also adopted, but it has a drawback of not being relevant to the in vivo physiological conditions, and an increase in variability was observed due to the interaction between some tablet excipients and the organic solvent. Adding a surfactant to the dissolution medium is the most commonly used method to provide sink conditions. Increased solubility after addition of surfactants may be explained by the ability of

*Corresponding author

Dissolution

Technologies NOVEMBER 2018

www.dissolutiontech.com 
the surfactants to increase the hydrophilicity of the drug and increase the micellar solubilization (8).

Candesartan cilexetil (CC) (BCS Class II drug) is considered one of the most potent and effective angiotensin-IIreceptor blockers. CC was first synthesized in 1993 and was demonstrated to be the most selective subtype 1 receptor blocker with the highest binding potency, maximal antagonism, and the longest dissociation time $(9,10)$. CC is a white crystalline powder with molecular weight of 610 , acid dissociation constant $(\mathrm{pKa})=6.0$, and it is practically insoluble in water and sparingly soluble in methanol $(11,12)$.

Only US FDA dissolution testing conditions for CC tablets were available until the release of the first supplement, USP39, in August 2016, which adopted the same conditions. The dissolution conditions were also not modified in the release of USP40. The USPspecified dissolution medium for 4, 8, and 16-mg tablets is $0.35 \%$ polysorbate 20 in $0.05 \mathrm{M}$ potassium

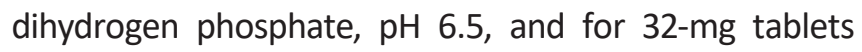
is $0.7 \%$ polysorbate 20 in the same, with acceptance tolerance not less than $80 \%$ dissolved after 45 minutes of dissolution (13).

Hoppe and Sznitowska evaluated the stability and the solubility of CC in the USP-specified medium and concluded that the chosen medium provides the best stability, as they detected degradation of candesartan cilexetil in acidic $\mathrm{pH}$ and noted that the addition of polysorbate meets sink conditions for the tested tablets (14). The same results were also reported by Kamalakkannan et al. (15). Another study was conducted by Hassan and colleagues in attempt to optimize the dissolution conditions of CC $16-\mathrm{mg}$ tablets, and they found that the concentration of polysorbate 20 in the dissolution medium is the major factor affecting the dissolution profile of CC rather than other testing parameters such as paddle rotation speed (16). They also suggested decreasing polysorbate 20 from $0.35 \%$ to $0.25 \%$ while testing 16-mg tablets to improve the discriminative power of the dissolution test (16). However, no research was reported in attempt to study the discriminative power of the 4- and 8-mg doses, which are worthy to study owing to the much higher percentage of polysorbate 20 used in the dissolution medium relative to the drug strength. Thus, the objective of this study was to evaluate the discriminative power of the USP-specified dissolution medium and attempt to develop a discriminating dissolution medium for the lower strengths of CC tablets, which might aid in the process of product development and improve the finished product quality.

\section{MATERIALS AND METHODS}

CC powder was obtained from Smilax Laboratories, Hyderabad, India. CC innovator brand was used for the reference product (16 mg, product A: $16 \mathrm{mg}$ Atacand tablets, batch no. 130194D2) and generic products (16 mg, products B, C, and D: batch nos. 456046, 183 3001, and A16101, respectively). CC tablets were purchased from the local market in Alexandria. Egypt. All other chemicals and reagents used were of analytical grade.

\section{Saturation Solubility Study}

The saturation solubility of CC was determined in phosphate buffer $\mathrm{pH} 6.5$ using different amounts of polysorbate 20 ( $0 \%, 0.1 \%, 0.35 \%, 0.5 \%, 0.7 \%$, and $1 \%)$. An excess quantity of CC powder was added to $25 \mathrm{~mL}$ of the selected medium in a stoppered conical flask then shaken in a thermostatically controlled mechanical shaker (Kottermann, type 3047, Germany) at $100 \mathrm{rpm}$ and $37 \pm$ $0.5^{\circ} \mathrm{C}$ for 24 hours. Samples were kept without stirring for another 24 hours then filtered through $0.22-\mu \mathrm{m}$ syringe filters. The solubility study was performed in triplicate, and the amount dissolved was detected using the high-performance liquid chromatography (HPLC) method in USP40 for detection of CC in the dissolution medium. The mobile phase composition was acetonitrile, trifluoroacetic acid, and water, 550:1:450 in a reversed phase column (X-Terra C18, $4.6 \mathrm{~mm} \times 15 \mathrm{~cm}, 5-\mu \mathrm{m}$ ) with temperature adjusted at $30{ }^{\circ} \mathrm{C}$, a flow rate of $1.5 \mathrm{~mL} /$ min, injection volume of $50 \mu \mathrm{L}$, and detection at $254 \mathrm{~nm}$ (Agilent 1200 series, Germany) (13).

\section{Testing the Discriminatory Power of USP Dissolution Method}

The dissolution study was conducted with CC 16-mg tablets, and fractions of tablets were used to obtain the lower strengths of 4 and $8 \mathrm{mg}$ to avoid the formulation effect on the release profile of CC. The fractions of tablets were checked by weight to ensure accurate subdivision prior to testing. The dissolution testing was performed using the recommended testing conditions by USP40 for 4, 8, and 16-mg doses, which are as follows: USP apparatus II (paddle) at $37 \pm 0.5^{\circ} \mathrm{C}$ with paddle speed of $50 \mathrm{rpm}$ in $900 \mathrm{~mL} 0.05 \mathrm{M}$ phosphate buffer, $\mathrm{pH}$ 6.5, with $0.35 \%$ polysorbate $20(n=12)$, using a dissolution test apparatus (Varrian, VK 7000/750D, Germany).

Samples of 5-mL were withdrawn at 5, 10, 20, 30, 45, and 60 minutes and filtered through $0.22-\mu \mathrm{m}$ syringe filters. Withdrawn samples were replaced with $5 \mathrm{~mL}$ of fresh dissolution medium to maintain sink conditions and constant dissolution medium volume. The amount dissolved was detected with the same previously mentioned HPLC method. 
Comparison of Dissolution Profiles by Similarity Factor This study utilized a model-independent approach in which the dissolution profiles of two drug products are compared using the similarity factor, $f 2$. The similarity factor directly compares the difference between percent drug dissolved per unit time for a test and a reference product. According to the findings of Vertzoni et al., when comparing cumulative drug release against time data, $f 2$ is more reliable than the difference factor $(f 1)(17)$. The similarity factor was calculated according to the following equation (18).

$$
f_{2}=50 \log \left\{\left[1+\left(\frac{1}{n}\right) \sum_{t=1}^{n}\left(R_{t}-T_{t}\right)^{2}\right]^{-0.5} \times 100\right\}
$$

where $(n)$ is the number of time intervals, $R_{\mathrm{t}}$ and $T_{\mathrm{t}}$ are the mean percent drug dissolved from the reference and the generic products at time interval $(t)$, respectively.

According to US FDA guidelines, dissolution testing of the test and reference products should be performed under the same conditions and time points for the dissolution profiles should be the same, with a minimum of three points, and only one measurement should be considered after $85 \%$ dissolution of both products. The two products are considered similar if $f 2$ is greater than or equal to 50 . Additionally, if both products dissolve at least $85 \%$ of the labeled drug amount within 15 minutes of dissolution, they are considered similar and no further testing or data analysis is required (19).

\section{Development of New Dissolution Medium for 4- and 8-mg Doses}

Fractions of the reference product resembling 4- and 8-mg doses ( $(1 / 2$ tablets for $8 \mathrm{mg}$ and $1 / 4$ tablets for $4 \mathrm{mg})$ were tested using the same conditions as the whole 16 $\mathrm{mg}$ tablet but with $0.1 \%$ polysorbate 20 instead of the USP-specified $0.35 \%$. Samples of $5 \mathrm{~mL}$ were withdrawn at the same time intervals then filtered through $0.22-\mu \mathrm{m}$ syringe filters. Withdrawn samples were replaced with 5 - $\mathrm{mL}$ of fresh dissolution medium and amount dissolved was detected with the same HPLC method $(n=12)$.

\section{Testing the Discriminatory Power of the Suggested Dissolution Medium}

Fractions of generic products previously tested in USP medium were used similarly to test the 4- and 8-mg doses in comparison to the reference product using the newly suggested percentage of polysorbate $20(0.1 \%)$. Samples of $5 \mathrm{~mL}$ were withdrawn at the same time intervals then filtered through $0.22-\mu \mathrm{m}$ syringe filters. Withdrawn samples were replaced with $5 \mathrm{~mL}$ of fresh dissolution medium and the amount dissolved was detected with the same HPLC method ( $n=12$ ).

\section{RESULTS AND DISCUSSION}

\section{Saturation Solubility Study}

The results of the saturation solubility study and the effect of polysorbate 20 , which is the surfactant selected by USP40, on sink conditions for CC at different strengths are summarized in Table 1 . The solubility of CC is directly proportional to the percentage of polysorbate 20 . The solubility markedly increased by increasing the percentage of polysorbate added from $0.091 \pm 0.008 \%$ in absence of polysorbate 20 to $24.83 \pm 0.387 \%$ in presence of $1 \%$ polysorbate 20 , with a 273 fold of enhancement, which could be explained by the increased micellar solubility. Hassan et al. reported nearly the same observations after testing CC solubility using polysorbate 20 with percentages of $0.25,0.35,0.45,0.55$, and $0.7 \%$ (16).

Table 1. Saturation Solubility Results and Relative Sink Conditions for Candesartan Cilexetil Tablets

\begin{tabular}{|c|c|c|c|c|c|}
\hline & $\begin{array}{c}\text { Average } \\
\text { Amount } \\
\text { Dissolved } \\
\text { Testing Medium }\end{array}$ & \multicolumn{4}{|c|}{$\begin{array}{c}\text { Number of Solubility Folds } \\
\text { for Different Strengths } \\
\left(\mathrm{C}_{\mathrm{s}} / \mathrm{C}_{\mathrm{d}}\right)\end{array}$} \\
\cline { 5 - 7 } & $\begin{array}{c}\text { (mean } \pm \\
\text { SD) }\end{array}$ & $4 \mathrm{mg}$ & $8 \mathrm{mg}$ & $\begin{array}{c}16 \\
\mathrm{mg}\end{array}$ & $\begin{array}{c}32 \\
\mathrm{mg}\end{array}$ \\
\hline Phosphate buffer pH 6.5 & $\begin{array}{c}0.091 \pm \\
0.008\end{array}$ & 0.20 & 0.10 & 0.05 & 0.03 \\
\hline $\begin{array}{c}\text { Phosphate buffer pH 6.5 } \\
\text { with 0.1\% polysorbate 20 }\end{array}$ & $\begin{array}{c}2.083 \pm \\
0.148\end{array}$ & 4.68 & 2.34 & 1.17 & 0.59 \\
\hline $\begin{array}{c}\text { Phosphate buffer pH 6.5 } \\
\text { with 0.35\% polysorbate 20 }\end{array}$ & $\begin{array}{c}9.657 \pm \\
0.232\end{array}$ & 21.74 & 10.87 & 5.43 & 2.72 \\
\hline $\begin{array}{c}\text { Phosphate buffer pH 6.5 } \\
\text { with 0.5\% polysorbate 20 }\end{array}$ & $\begin{array}{c}15.24 \pm \\
0.511\end{array}$ & 34.29 & 17.15 & 8.57 & 4.29 \\
\hline $\begin{array}{c}\text { Phosphate buffer pH 6.5 } \\
\text { with 0.7\% polysorbate 20 }\end{array}$ & $\begin{array}{c}20.60 \pm \\
0.775\end{array}$ & 46.13 & 23.06 & 11.53 & 5.77 \\
\hline $\begin{array}{c}\text { Phosphate buffer pH 6.5 } \\
\text { with 1\% polysorbate 20 }\end{array}$ & $\begin{array}{c}24.83 \pm \\
0.387\end{array}$ & 55.87 & 27.93 & 13.97 & 6.98 \\
\hline
\end{tabular}

$C_{s}$, saturation solubility of CC in $900 \mathrm{~mL}$ dissolution medium; $C_{d}$, dose of $C C$ in tablet formulation. Shaded cells represent the sink condition in the official USP4O medium for each strength.

\section{Testing the Discriminatory Power of USP Dissolution} Method

To evaluate the ability of the dissolution medium to discriminate the difference in release profiles of different products with different strengths while avoiding the formulation effect, dissolution of 4- and 8-mg doses from different generic products were tested using fractions of 


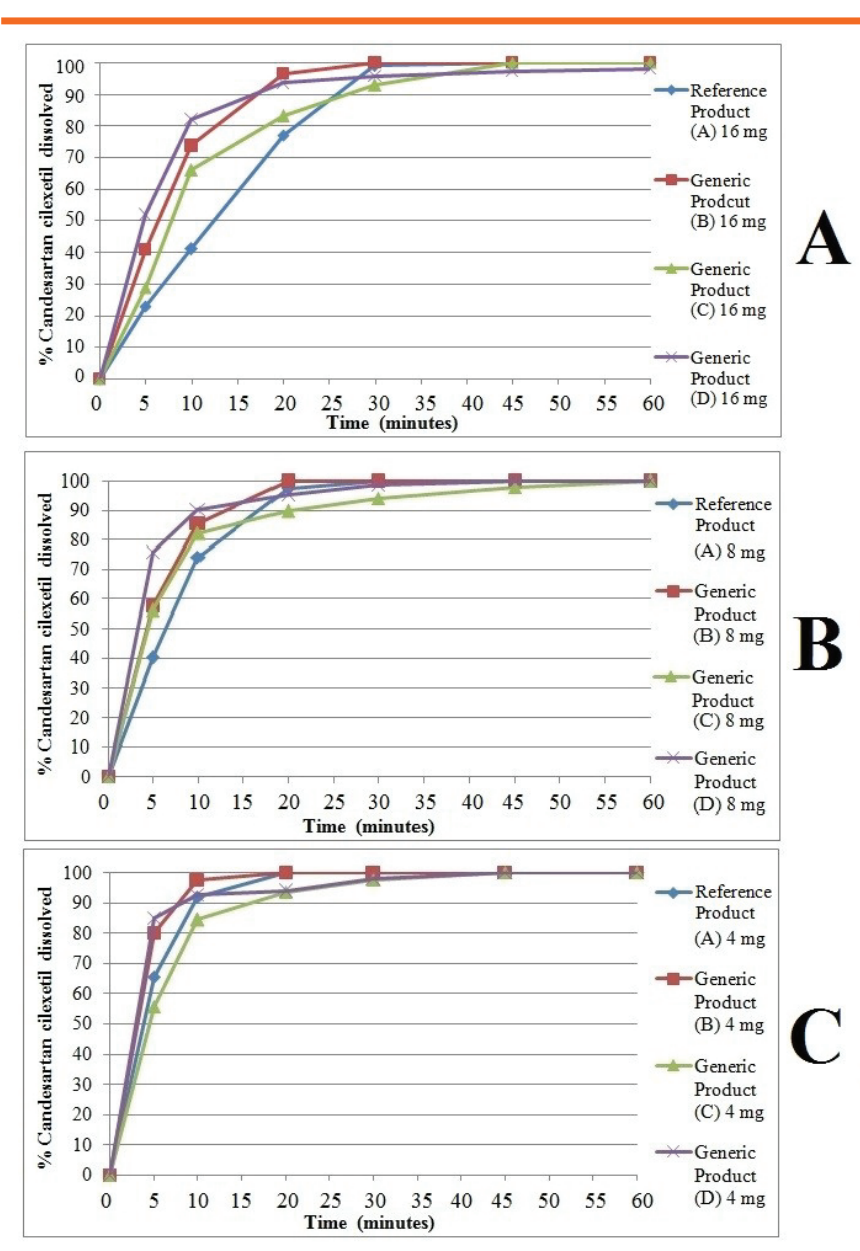

Figure 1. Dissolution profiles of candesartan cilexetil $16 \mathrm{mg}(A), 8 \mathrm{mg}(B)$, and $4 \mathrm{mg}(C)$ in USP-specified dissolution medium (phosphate buffer pH 6.5 with $0.35 \%$ polysorbate 20$)(n=12)$.

Table 2. Amount of Drug Dissolved After 45 Minutes of Dissolution and Time for 80\% Drug Dissolved from Candesartan Cilexetil Tablets Using USP4O Dissolution Method $(n=12)$

\begin{tabular}{|c|c|c|c|c|c|c|}
\hline \multirow{2}{*}{ Tested Product } & \multicolumn{3}{|c|}{$\begin{array}{c}\text { Amount of Candesartan } \\
\text { Cilexetil Dissolved After 45 } \\
\text { min (\%) } \\
\text { (mean } \pm \text { SD) }\end{array}$} & \multicolumn{3}{c|}{$\begin{array}{c}\text { Time for 80\% } \\
\text { Candesartan } \\
\text { Cilexetil Dissolved } \\
\left(T_{80 \%)}\right. \\
(\mathrm{min})\end{array}$} \\
\cline { 2 - 7 } & $16 \mathrm{mg}$ & $8 \mathrm{mg}$ & $4 \mathrm{mg}$ & $\begin{array}{c}16 \\
\mathrm{mg}\end{array}$ & $\begin{array}{c}8 \\
\mathrm{mg}\end{array}$ & $\begin{array}{c}4 \\
\mathrm{mg}\end{array}$ \\
\hline $\begin{array}{c}\text { Reference } \\
\text { Product A }\end{array}$ & $\begin{array}{c}100.59 \\
\pm 1.32\end{array}$ & $\begin{array}{c}99.81 \pm \\
1.75\end{array}$ & $\begin{array}{c}101.93 \\
\pm 2.25\end{array}$ & 21.5 & 12.5 & 7.5 \\
\hline $\begin{array}{c}\text { Generic } \\
\text { Product B }\end{array}$ & $\begin{array}{c}101.44 \\
\pm 2.19\end{array}$ & $\begin{array}{c}102.70 \\
\pm 2.62\end{array}$ & $\begin{array}{c}101.57 \\
\pm 1.88\end{array}$ & 12.75 & 9.25 & 5.25 \\
\hline $\begin{array}{c}\text { Generic } \\
\text { Product C }\end{array}$ & $\begin{array}{c}100.07 \\
\pm 1.53\end{array}$ & $\begin{array}{c}98.87 \pm \\
2.04\end{array}$ & $\begin{array}{c}99.40 \pm \\
1.96\end{array}$ & 18.25 & 9.75 & 9.0 \\
\hline $\begin{array}{c}\text { Generic } \\
\text { Product D }\end{array}$ & 97.43 & $96.56 \pm$ & $96.74 \pm$ & 9.5 & 6.5 & 4.75 \\
\hline
\end{tabular}

16-mg tablets. The release profiles of each dose in the USP-specified dissolution medium are presented in Figure 1. The mean percent $\mathrm{CC}$ dissolved from each product after 45 minutes and time required for $80 \%$ dissolution of CC $\left(T_{80 \%}\right)$ are presented in Table 2 .

From the obtained dissolution profiles of $16-\mathrm{mg}$ tablets, and according to the previously mentioned guidelines, only the $5,10,20$, and 30 minute-time points were considered to calculate $f 2$. Despite the ability of different 16 -mg products to pass the USP40 monograph dissolution test limit, none were similar to the reference product, showing $f 2$ values of $33.80,43.34$, and 28.83 for generic products B, C, and D, respectively. However, for the 4 and 8-mg doses, all generic products are considered similar to the reference product, as they all demonstrated more than $85 \%$ dissolution within the first 15 minutes of testing without any formula alteration.

Additionally, the obtained dissolution profiles revealed distinctive behavior and differences between the different strengths, which is further confirmed by the results presented in Table 2. The time required for the $16-\mathrm{mg}$ products to reach $\mathrm{T}_{80 \%}$ ranged from 9.5 to 21.5 minutes, with a difference of nearly 12 minutes between the first and last product. However, this difference decreased by half to only 6 minutes when testing the 8-mg strength and further decreased to nearly 4 minutes with the 4-mg strength.

The previous observations suggest the poor ability of the pharmacopeial dissolution testing conditions to provide an appropriate segregation between the different products especially at the lower strengths, where the three generic products were dissimilar to the reference product when testing the 16-mg doses and the formulas were similar to the reference product in the 4 and 8-mg doses due to the high ratio of the surfactant to the drug tested. Despite the ability of the USP-specified medium to provide a reasonable sink condition for $16-\mathrm{mg}$ strength tablets with 5.43-fold solubility, the sink condition becomes excessive by decreasing the strength to $4 \mathrm{mg}$ while maintaining the same percentage of polysorbate 20 , resulting in 21.74-fold solubility.

The effect of polysorbate 20 on the dissolution rate of 4,8 , and 16-mg doses with the same formula as the reference product is obvious in Figure $2 \mathrm{~A}$, where $T_{80 \%}$ decreased from 21.5 minutes with $16-\mathrm{mg}$ tablets to 7.5 and 12.5 minutes with 4 and 8-mg tablets, respectively. Furthermore, percent CC dissolved after 10 minutes 
increased from only $41.11 \%$ dissolved from the $16-\mathrm{mg}$ tablets to $91.8 \%$ and $74.27 \%$ dissolved from the 4 and 8-mg doses, respectively.

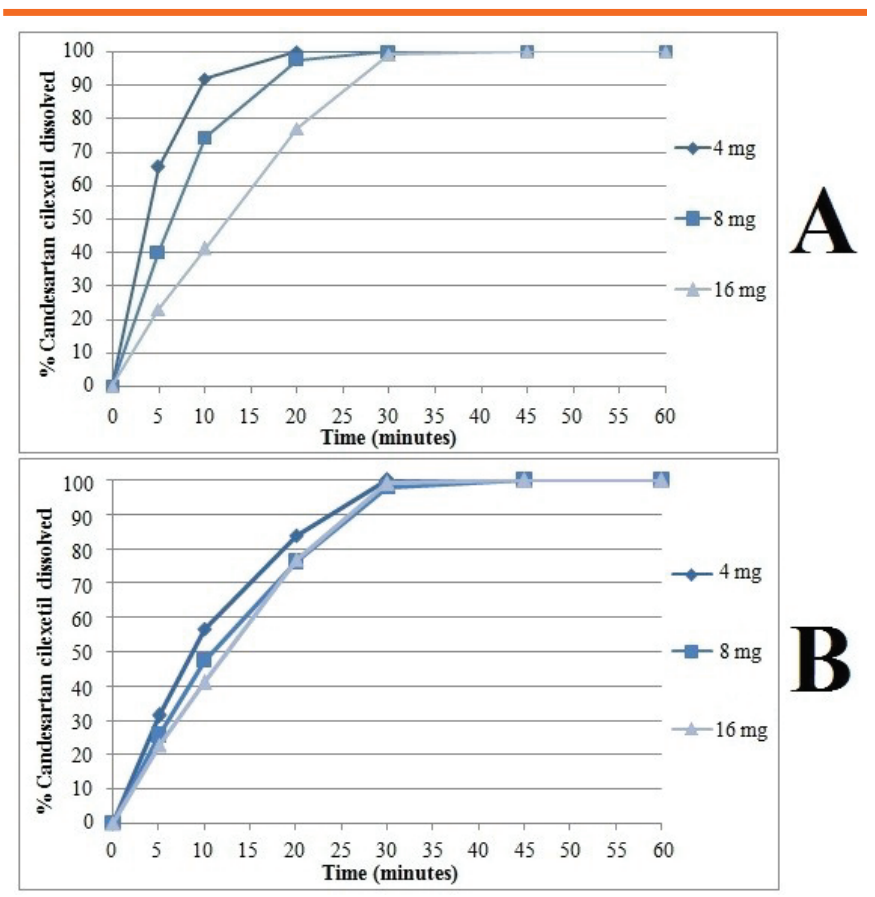

Figure 2. A: Dissolution profiles of 4-, 8-, and 16-mg reference products in $0.35 \%$ polysorbate 20 . B: Dissolution profiles of 4 and $8 \mathrm{mg}$ reference products in $0.1 \%$ polysorbate 20 compared to $16-\mathrm{mg}$ strength in $0.35 \%$ polysorbate $20(n=12)$.

\section{Development of New Dissolution Medium for 4 and 8 mg Tablets}

The concentration of polysorbate 20 recommended by the US FDA and USP40 is much higher than the critical micelle concentration, which ranges from $0.07 \%$ to $0.09 \%$ according to the USP (7). Therefore, $0.1 \%$ polysorbate 20 was selected for testing 4- and 8-mg doses instead of $0.35 \%$, as $0.1 \%$ is just above the critical micelle concentration of polysorbate 20.

The dissolution profiles of the 4- and 8-mg doses of the reference product in $0.1 \%$ polysorbate 20 are presented in comparison to the $16-\mathrm{mg}$ tablets in $0.35 \%$ polysorbate 20 in Figure 2B. Moreover, $\mathrm{T}_{80 \%}$ and $f 2$ for the lower strengths of 4 and $8 \mathrm{mg}$ in $0.1 \%$ polysorbate 20 were calculated in comparison to the 16 -mg profile in the USPspecified medium. The resulting dissolution profiles for the lower strengths after testing in $0.1 \%$ polysorbate 20 revealed a similar pattern to the profile of $16-\mathrm{mg}$ tablet of the same formula, where the profile of $8-\mathrm{mg}$ dose is nearly superimposed with an $f 2$ of 71.66 and the 4-mg dose was nearly similar with an $f 2$ of 51.02 . Moreover, differences in $\mathrm{T}_{80 \%}$ reduced from nearly 14 minutes when testing in the USP-specified medium to only 3.5 minutes in $0.1 \%$ polysorbate 20 , as $\mathrm{T}_{80 \%}$ increased from 7.5 and 12.5 minutes in the official medium to 18.5 and 22 minutes in $0.1 \%$ polysorbate 20 , for the $4-$ and 8 -mg strengths, respectively, which is very close to $T_{80 \%}$ of the $16-\mathrm{mg}$ tablet (21.5 minutes) in the USP medium. The obtained results demonstrate the influence of polysorbate 20 on the dissolution profile of $\mathrm{CC}$ and suggest the suitability of the $0.1 \%$ polysorbate 20 for testing the lower strengths of 4 and $8 \mathrm{mg}$.

\section{Testing the Discriminatory Power of the Suggested Dissolution Medium}

The dissolution profile of the 4 and 8 -mg products in $0.1 \%$ polysorbate 20 are presented in Figure 3 , and $f 2$ for each product was calculated in comparison to the reference product. The obtained release profiles demonstrate an acceptable sink condition, where all the tested products were able to pass the USP performance test limit with more than $80 \%$ dissolved after 45 minutes. The dissolution profiles also demonstrated a distinctive pattern for each formula, proving the ability of $0.1 \%$ polysorbate 20 to provide a reasonable sink condition and improve the discriminative ability of the dissolution medium, resulting in an $f 2$ less than 50 for all marketed products. The 4-mg generic products $B, C$, and $D$ had an $f 2$ of $45.59,43.96$, and 29.17 , respectively, and the 8 -mg generic products were 48.54, 42.42, and 31.63, respectively. Moreover, the obtained results demonstrated that the dissolution behavior of CC is not only dependent on the sink condition but also on the ratio of the drug to the surfactant, which is obvious when comparing the release profile of the $4-\mathrm{mg}$ product $\mathrm{C}$ in $0.1 \%$ polysorbate 20 with the $16-\mathrm{mg}$ strength in $0.35 \%$ polysorbate 20 , as presented in Figure 4. Notice that the sink condition is nearly the same in both cases, with 4.68- and 5.43-fold solubility, respectively. The slower dissolution rate of the 4-mg strength in $0.1 \%$ polysorbate 20 could be explained by the low availability of excess polysorbate in the bulk of the medium to form micelles unlike the $0.35 \%$, which is much higher than the critical micelle concentration of polysorbate 20 , resulting in improved solubility by micellar solubilization.

\section{CONCLUSION}

The discriminatory power of the dissolution testing is very important to demonstrate the effect of formula changes on the dissolution profile. However, the addition of surfactants to improve the solubility and provide sink conditions for poorly water soluble drugs like CC could dramatically hinder the discriminating ability of the medium. This work demonstrated the poor discriminating ability of the specified dissolution medium by USP40 for CC 4 and 8 -mg doses (fractions of 16-mg tablets) and suggests the use of $0.1 \%$ of polysorbate 20 . 


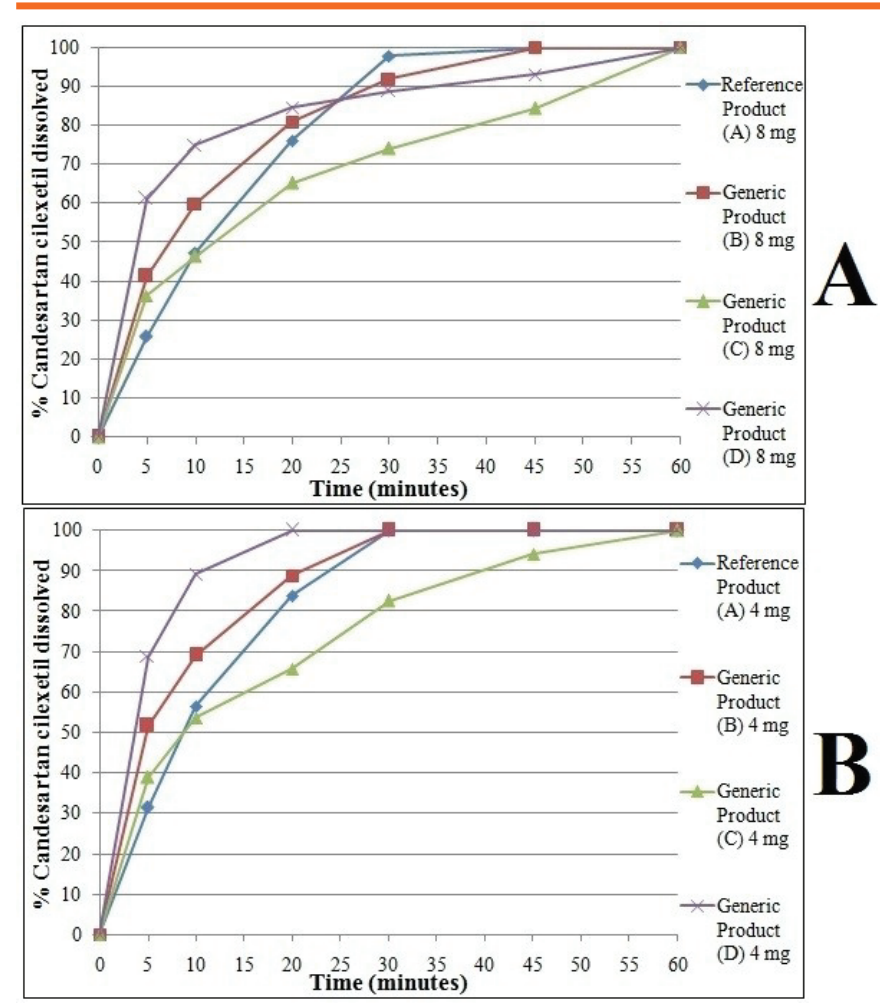

Figure 3. Dissolution profiles of candesartan cilexetil $8 \mathrm{mg}(\mathrm{A})$ and $4 \mathrm{mg}$ $(B)$ in the suggested medium (phosphate buffer pH 6.5 with $0.1 \%$ polysorbate 20$)(n=12)$.

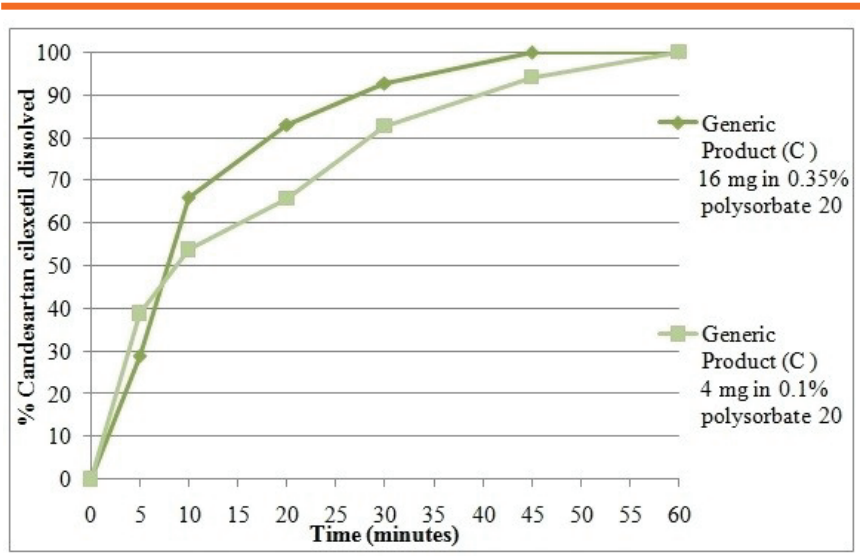

Figure 4. Dissolution profiles of candesartan cilexetil generic product $\mathrm{C}$ at $16 \mathrm{mg}$ and $4 \mathrm{mg}$ in phosphate buffer $\mathrm{pH} 6.5$ with $0.35 \%$ and $0.1 \%$ polysorbate 20 , respectively $(n=12)$.

\section{ACKNOWLEDGEMENTS}

The authors disclosed no funding related to this article.

\section{CONFLICT OF INTEREST}

The authors disclosed no conflicts of interest related to this article.

\section{REFERENCES}

1. Cohen, J. L.; Hubert, B. B.; Leeson, L. J.; Rhodes, C. T.; Robinson, J. R.; Roseman, T. J.; Shefter, E. The development of USP dissolution and drug release standards. Pharm. Res. 1990, 7, 983-987. DOI: 10.1023/A:1015922629207.

2. Anand, O.; Yu, L. X.; Conner, D. P.; Davit, B. M. Dissolution testing for generic drugs : an FDA perspective. AAPS J. 2011, 13, 328335. DOI: 10.1208/s12248-011-9272-y.

3. Bajerski, L.; Rossi, R. C.; Dias, C. L.; Bergold, A. M.; Fröehlich, P. E. Development and validation of a discriminating in vitro dissolution method for a poorly soluble drug, olmesartan medoxomil: comparison between commercial tablets. AAPS J. 2010, 11, 637-644. DOI: 10.1208/s12249-010-9421-0.

4. Qureshi, S. A. In vitro-in vivo correlation (IVIVC) and determining drug concentrations in blood from dissolution testing-a simple and practical approach. Open Drug Deliv. J. 2010, 4, 38-47. DOI: $10.2174 / 1874126601004020038$.

5. Janssens, S.; Van den Mooter, G. Review: physical chemistry of solid dispersions. J. Pharm. Pharmacol. 2009, 61, 1571-1586. DOI: 10.1211/jpp/61.12.0001.

6. Soni, T.; Nagda, C.; Gandhi, T.; Chotai, N. Development of discriminating method for dissolution of aceclofenac marketed formulations. Dissolution Technol. 2008, 15, 31-35. DOI: 10.14227/DT150208P31.

7. <1092> The Dissolution Procedure: Development and Validation. In The Uniuted States Pharmacopeia and National Formulary USP4O-NF35; The United States Pharmacopeial Convention, Inc: Rockville, MD, 2017.

8. Phillips, D. J.; Pygall, S. R.; Cooper, V. B.; Mann, J. C. Overcoming sink limitations in dissolution testing: a review of traditional methods and the potential utility of biphasic systems. J. Pharm. Pharmacol. 2012, 64, 1549-1559. DOI: 10.1111/j.20427158.2012.01523.x.

9. Easthope, S. E.; Jarvis, B. Candesartan cilexetil: an update of its use in essential hypertension. Drugs. 2002, 62, 1253-1287. DOI: 10.2165/00003495-200262080-00016.

10. Cernes, R.; Mashavi, M.; Zimlichman, R. Differential clinical profile of candesartan compared to other angiotensin receptor blockers. Vasc. Health Risk Manag. 2011, 7, 749-759. DOI: 10.2147/VHRM.S22591.

11. Raghad, A.; Hind, E. Enhancement of candesartan cilexetil dissolution rate by using different methods. Asian J. Pharm. Clin. Res. 2015, 8, 320-326.

12. Gleiter, C. H.; Jägle, C.; Gresser, U.; Mörike, K. Candesartan. Cardiovasc. Drug Rev. 2004, 22, 263-284. DOI: 10.1111/j.15273466.2004.tb00146.x.

13. Candesartan Cilexetil Tablets Monograph. In The United States Pharmacopeia and National Formulary USP40-NF35; The United States Pharmacopeial Convention, Inc: Rockville, MD, 2017.

14. Hoppe, K.; Sznitowska, M. The effect of polysorbate 20 on solubility and stability of candesartan cilexetil in dissolution media. AAPS J. 2014, 15, 1116-1125. DOI: 10.1208/s12249-0140109-8. 
15. Kamalakkannan, V.; Puratchikody, A.; Ramanathan, L. Development and validation of a dissolution test with reversedphase high performance liquid chromatographic analysis for candesartan cilexetil in tablet dosage forms. Arab J. Chem. 2011, 9, 867-873. DOI: 10.1016/j.arabjc.2011.09.011.

16. Hassan, H. A.; Charoo, N. A.; Ali, A. A.; Alkhatem, S. S. Establishment of a bioequivalence- indicating dissolution specification for candesartan cilexetil tablets using a convolution model. Dissolution Technol. 2015, 22, 36-43. DOI: 10.14227/ DT220115P36.

17. Vertzoni, M.; Symillides, M.; Iliadis, A.; Nicolaides, E.; Reppas, C. Comparison of simulated cumulative drug versus time data sets with indices. Eur. J. Pharm. Biopharm. 2003, 56, 421-428. DOI: 10.1016/S0939-6411(03)00141-3.

18. Doriguetto, C. A discriminating dissolution method for glimepiride. J. Pharm. Sci. 2012, 101, 794-804. DOI: 10.1002/
Software for the in vitro dissolution experiment of pharmaceutical dosage forms

\section{NEW in DDDPlus version 6:}

- NEW mechanistic Artificial Stomach-Duodenum model

- NEW in vitro dissolution apparatus models for improved

IVIVE of precipitation kinetics with GastroPlus ${ }^{\mathrm{m}}$ :

- Biphasic dissolution

- Membrane dissolution

- NEW controlled release and Long Acting Injectable dosage form models

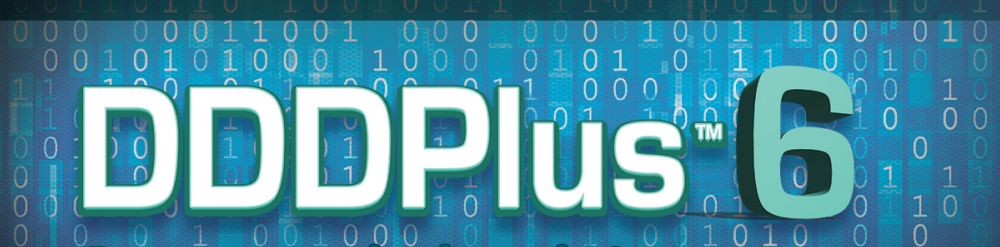

Request an evaluation today?

www.simulations-plus.com/dddplus
5)+ SimulationsPlus

SCIENCE + SOFTWARE $=$ SUCCESS 